\title{
Risk Profile of Bony Intervention for Hip Displacement in our Youngest Cohort of Children with Cerebral Palsy
}

\author{
Manuel Johannes Kraus ${ }^{1,2 *}$, Reinald Brunner ${ }^{1,2}$ and Erich Rutz ${ }^{1-3}$ \\ ${ }^{1}$ University Children's Hospital Basel, UKBB, Paediatric Orthopaedics, Switzerland \\ ${ }^{2}$ University of Basel, Switzerland
}

${ }^{3}$ Murdoch Children's Research Institute, The Royal Children's Hospital Melbourne, Australia

*Corresponding author: Manuel Johannes Kraus, University Children's Hospital Basel, UKBB, Paediatric Orthopaedics, Spitalstrasse 33, PO Box CH 4031 Basel, Switzerland

\begin{tabular}{l}
\hline ARTICLE INFO \\
\hline Received: 1 April 03, 2019 \\
Published: April 15, 2019 \\
\hline Citation: Manuel Johannes Kraus, Rein- \\
ald Brunner, Erich Rutz. Risk Profile of \\
Bony Intervention for Hip Displacement \\
in our Youngest Cohort of Children with \\
Cerebral Palsy. Biomed J Sci \& Tech Res \\
17(1)-2019. BJSTR. MS.ID.002946.
\end{tabular}

Keywords: Cerebral Palsy; Hip Reconstruction; Hip Surgery; Risk Profile
ABSTRACT

Background: Children with higher GMFCS level frequently suffer from progressive hip displacement. A common consequence is pain affecting the ability to sit, compromising care and thereby, impairing quality of life. While other treatments often fail, bony reconstructive surgery is able to sufficiently ease pain and restore the range of motion. Our study presents our experience with these bony procedures in our youngest patients.

Methods: 76 procedures (41 hip reconstructions, 35 femoral osteotomies) in 39 patients aged 2 to 8 years (median 5) were studied. Surgical procedure duration and blood loss were recorded. Complication rates of the immediate postoperative course as well as the radiological outcomes of this cohort in the short-term 4 to 13 months postoperatively (median 9) are reported.

Results: The overall operation time per hip (median 100min) and blood loss per procedure (median $10.4 \mathrm{ml} / \mathrm{kgBW}$ ) was satisfactory, however the complication rate was in total $70 \%$ including mild and moderate complications (grades I-III) in $66 \%(n=27)$ and severe complications (grades IV and V) in $4 \%(n=2)$ of patients according to the modified Clavien-Dindo classification. Radiographs confirmed a favourable reconstruction of bony hip biomechanics especially in combined pelvic and femoral procedures.

Conclusions: Reconstructive hip surgery in young $\mathrm{CP}$ patients is challenging not only in terms of the procedure but also concerning management in the peri- and postoperative course. Management in an interdisciplinary setting including initial postoperative ICU admission, a low threshold for blood transfusions and an experienced surgeon is required.

Abbreviations: CP: Cerebral Palsy; GMFCS: Gross Motor Function Classification System; MCPHCS: Melbourne Cerebral Palsy Hip Classification System; BMI: Body Mass Index; VDO: Varus Derotation Osteotomy; AI: Acetabular Index; ASA: American Society of Anesthesiologists Physical Status Classification System; AVN: Avascular Necrosis; ICU: Intensive Care Unit; MP: Migration Percentage

\section{Introduction}

As the leading cause of physical disability during childhood, cerebral palsy (CP) has a high impact on healthcare costs $[1,2]$ and efficient management must therefore be a priority. This includes keeping extensive and repetitive surgical procedures to a minimum. Hip displacement is common in children with CP and is directly related to gross motor function represented by the Gross Motor Function Classification System (GMFCS)-level [3,4]. Rutz et al. have shown that each one year decrease in patient age at surgery corresponded to a 6.3\% decrease in MCPHCS (Melbourne Cerebral Palsy Hip Classification System) improvement [5,6] at the final follow-up. But there are those cases where conservative treatment regimens or procedures addressing the soft tissues cannot avoid rapid progress, pain or early structural damage, which leads to the necessity of open surgical treatment of displaced hips in early childhood. Good long-term outcomes with these procedures in younger children have been reported [7].

In contrast recent literature further shows doubtful outcomes after conservative treatment: There is no proof for the benefit of orthotic devices, while botulinum toxin is not effective [8], and adductor surgery is effective in ambulant children only [9]. For this 
reason, early hip displacement especially in the severely affected patient often with reduced general health compared to healthy peers is inevitable and may force the orthopaedic surgeon toward early intervention due to pain or functional loss. The objective of this study was to evaluate the feasibility of bony procedures in our youngest patients with early hip displacement. We analysed the duration of the surgical procedure and blood loss. In addition, we evaluated the complication rates of the immediate postoperative course as well as the radiographic outcomes of this cohort.

\section{Methods}

We included patients undergoing reconstructive surgery of the hip between August 2008 and June 2015 who met the following inclusion criteria: confirmed diagnosis of cerebral palsy, age 2 to 8 years and at least one hip exceeding Reimer's MP of 30\% [10]. Patients with previous interventions on the same hip or incomplete clinical datasets were excluded. Prospectively collected data of 39 patients (21 male/18 female) corresponding to 76 hips and 41 onestage surgeries could be included and analysed. Of the 39 patients thirty-three (85\%) were affected by spastic CP while four $(10 \%)$ suffered from hypotonic and two (5\%) from dyskinetic types. Looking at the distribution thirty-six (92\%) had bilateral CP with total body involvement and three (8\%) bilateral CP with lower limb involvement. Even though the GMFCS-levels ranged from I to $\mathrm{V}$ the vast majority ranged in higher levels with ten $(25 \%)$ being classified as level IV and twenty-three (59\%) as level V. Preoperative judgement of the physical status by the responsible anaesthetists resulted in an ASA-Score (American Society of Anesthesiologists physical status classification system) [11] of II in seventeen patients (44\%) and III in 22 patients (56\%).

As a further parameter of the physical pre-condition the bodyweight at the date of surgery ranged between 7 and $30 \mathrm{~kg}$. The BMI (body mass index) [12] was only applicable in 31 patients because of missing documentation of body height or length. The range was BMI 10.4 to $19.3 \mathrm{~kg} / \mathrm{m}^{2}$ with a median of $14.9 \mathrm{~kg} / \mathrm{m}^{2}$. As the BMI in young people aged 2-20 years cannot be interpreted like in adults, a closer inspection utilising age- and sex-related percentiles is needed [13]. Of the aforementioned 31 patients ten $(32 \%)$ ranged below the $3^{\text {rd }}$ percentile, three $(10 \%)$ were between the $5^{\text {th }}$ and $10^{\text {th }}$ and another three $(10 \%)$ between the 10 th and 25 th percentile. Six $(20 \%)$ reached the $25^{\text {th }}$ to $50^{\text {th }}$ percentile and five $(16 \%)$ the $50^{\text {th }}$ to $75^{\text {th }}$ percentile. Between $75^{\text {th }}$ and $85^{\text {th }}$ there were two $(6 \%)$ and between $85^{\text {th }}$ and $90^{\text {th }}$ as well as above the $97^{\text {th }}$ percentile just $1(3 \%)$ patient. No patients were classified as $3^{\text {rd }}$ to $10^{\text {th }}$ or $90^{\text {th }}$ to $97^{\text {th }}$ percentile. As expected in this cohort almost one third was underweight compared to peers and more than two thirds ranged below the $50^{\text {th }}$ percentile (Table 1 ).

Postoperative surveillance in ICU for at least one night is standard in our hospital for these procedures. Patients who leave theatre early and have a very good physical status may be admitted to the ward the same day. Therefore, the range of nights in ICU of the reported cohort is 0 to 35 nights with a median of 1 night. One patient was admitted to ICU for the entire duration of the hospital admission (35 nights) due to the complexity of required treatment. This patient had respiratory insufficiency necessitating chronic ventilation via tracheal cannula, nutrition via a gastric feeding tube and observation because of frequent seizures. At discharge he returned to his baseline function. He was noted to have developed a sacral decubitus ulcer in the spica cast but this healed prior to discharge while hip pain could be reduced by right-sided hip reconstruction and contralateral varus derotation osteotomy (VDO). None of the other patients had to stay in ICU for more than 5 nights with eight (20\%) being admitted to the ward the same day and twenty-four (59\%) staying for 1 night as scheduled.

Table 1: Patient Demographics $(n=39)$.

\begin{tabular}{|c|c|}
\hline Median age at surgery (yr) & $5(2$ to 8$)$ \\
\hline Sex & $21 \mathrm{M}, 18 \mathrm{~F}$ \\
\hline Cerebral palsy type & $\begin{array}{l}33 \text { spastic, } 4 \text { hypotonic, } 2 \\
\text { dyskinetic }\end{array}$ \\
\hline Topographical distribution & $\begin{array}{l}36 \text { total body, } 3 \text { bilateral lower } \\
\text { limb }\end{array}$ \\
\hline Median GMFCS level & $\mathrm{V}(\mathrm{I}$ to $\mathrm{V})$ \\
\hline ASA* status & 22 ASA III, 17 ASA II \\
\hline Median bodyweight at surgery (kg) & 16 (7 to 30$)$ \\
\hline \multicolumn{2}{|c|}{$\begin{array}{c}\text { *ASA: American Society of Anesthesiologists physical status } \\
\text { classification system }\end{array}$} \\
\hline
\end{tabular}

In order to analyse the addressed pathologies in a consistent manner the expanded and revised MCPHCS [5, 14] was applied. MCPHCS grade 1, defined by a migration percentage below $10 \%$, represents the normal hip. These hips were only addressed if a coxa valga was present to restore symmetry in combination with the more severely affected contralateral side. MCPHCS grades 2 ( $M P \geq 10$ to $\leq 15 \%$ ) and 3 (MP $>15$ to $\leq 30 \%$ ) were summarised and termed hip displacements. Grades 4 (MP $>30$ to $<60 \%$ ) and 5 (MP $\geq 60$ to $<100 \%$ ) were both described as hip subluxations and grade 6 (MP $\geq 100 \%$ ) was termed hip dislocation. The cohort consists of seventeen (22\%) dislocations, forty (53\%) subluxations, sixteen (21\%) displacements and three (4\%) hips with coxa valga. At the femur either a shortening VDO (71 cases, 93\%) or a VDO without additional shortening ( 5 cases, $7 \%$ ) was performed. When shortening was necessary for symmetry reasons or due to expected high pressure after joint reduction, the shortening distance ranged between 2 to $20 \mathrm{~mm}$ (median $10 \mathrm{~mm}$ ). The femoral osteotomies were fixed with Synthes ${ }^{\circledR}$ AO blade plates in 50 cases (66\%) [1517], 3.5mm LCP pediatric hip plates in 25 cases (33\%) and in 1 case with the $2.7 \mathrm{~mm}$ LCP pediatric hip plate (1\%) [18].

If acetabular deformity was evident, pelvic Pemberton osteotomies were carried out. This was required in 41 hips, of which 18 hips were in 9 patients where bilateral treatment was required. For the Pemberton osteotomy the wedge from the femoral osteotomy was used and fixed by K-wires if necessary. The combination of femoral and pelvic osteotomy is referred to as hip reconstruction. In these 41 hips twenty-six (63\%) required open reduction. Of thirty-nine (51\%) left-sided procedures twentyone (54\%) were hip reconstructions and eighteen (46\%) femoral osteotomy only. The 37 (49\%) right-sided interventions consisted of twenty (54\%) hip reconstructions and seventeen (46\%) femoral osteotomies. Six hips (8\%) were additionally treated with adductor lengthening because passive abduction of $\geq 20^{\circ}$ was not reached after hip reconstruction (Table 2). The 39 patients / 76 hips were 
treated with 41 one-stage surgeries, nineteen (46\%) of which had hip reconstruction on one side and contralateral femoral osteotomy. Nine $(22 \%)$ needed bilateral hip reconstructions and seven (17\%) bilateral femoral osteotomies.

Table 2: Procedures $(n=76)$.

\begin{tabular}{|c|c|}
\hline Pathology & $\begin{array}{c}17 \text { dislocations, } 40 \text { subluxations, } 16 \\
\text { displacements, } 3 \text { coxae valga (indication: } \\
\text { symmetry) }\end{array}$ \\
\hline Side & $\begin{array}{l}39 \text { left: } 21 \text { hip reconstructions, } 18 \text { femur only } \\
37 \text { right: } 20 \text { hip reconstructions, } 17 \text { femur only }\end{array}$ \\
\hline Pemberton & 41 ( 9 bilateral cases, 26 open reduction) \\
\hline Femoral osteotomy & 71 shortening VDOs*, 5 VDOs \\
\hline $\begin{array}{l}\text { Median shortening } \\
\text { (mm) }\end{array}$ & $10(2$ to 20$)$ \\
\hline Implants & 50 AO-blade plate, 26 LCP pediatric hip plate \\
\hline $\begin{array}{l}\text { Soft tissue } \\
\text { procedures }\end{array}$ & 6 adductor lengthenings \\
\hline \multicolumn{2}{|c|}{ *VDO: varus derotation osteotomy } \\
\hline
\end{tabular}

Table 3: One-stage surgeries $(n=41)$.

\begin{tabular}{|c|c|c|}
\hline & Side 1 & Side 2 \\
\hline 19 & Hip reconstruction & Femoral osteotomy \\
\hline 9 & Hip reconstruction & Hip reconstruction \\
\hline 7 & Femoral osteotomy & Femoral osteotomy \\
\hline 4 & Hip reconstruction & - \\
\hline 2 & Femoral osteotomy & - \\
\hline \multicolumn{2}{|c|}{ Spica cast (median, range/weeks) } & 25 cases $(2,1-6)$ \\
\hline
\end{tabular}

Table 4: Surgical Complications/ Clavien-Dindo $(n=41)$.

\begin{tabular}{|c|c|c|c|}
\hline Grade I & $5 \%$ & $(n=2)$ & $\begin{array}{l}\text { 1x prolonged severe vomiting } 1 \mathrm{x} \\
\text { skin mycosis }\end{array}$ \\
\hline Grade II & $61 \%$ & $(n=25)$ & $\begin{array}{c}23 \mathrm{x} \text { blood transfusion } \\
2 \mathrm{x} \text { pneumonia } \\
\text { 2x rise of intensity and frequency } \\
\text { of seizures needing adjustment of } \\
\text { drug regimen } \\
2 \mathrm{x} \text { decubitus related to Spica } \\
\text { casting } \\
1 \mathrm{x} \text { severe desaturations } \\
1 \mathrm{x} \text { paralytic ileus }\end{array}$ \\
\hline Grade III & - & $(-)$ & - \\
\hline Grade IV & $2 \%$ & $(n=1)$ & $\begin{array}{l}\text { mechanical ileus caused by jejunal } \\
\text { feeding tube, requiring laparotomy } \\
\text { followed by sepsis }\end{array}$ \\
\hline Grade V & $2 \%$ & $(n=1)$ & $\begin{array}{l}\text { severe pneumonia leading to } \\
\text { cardiopulmonary decompensation, } \\
\text { died } 7 \text { days postoperatively }\end{array}$ \\
\hline Total & $70 \%$ & 29 & \\
\hline
\end{tabular}

Four $(10 \%)$ patients had one-sided hip reconstructions and 2 (5\%) had one-sided femoral osteotomies only. Twenty-five (61\%) of these one-stage procedures had after-care in a Spica cast for 1-6 weeks (median 2 weeks). (Table 3) Procedure duration was recorded in minutes (min) from the first incision and ending with the last wound suture on the same side. Blood loss was recorded in millilitres $(\mathrm{ml})$ for the whole procedure be it one-sided or bilateral and adjusted to the patient's bodyweight (millilitres per kilogram bodyweight $=\mathrm{ml} / \mathrm{kgBW}$ ). Complications were documented during the postoperative course and graded according to the modified Clavien-Dindo classification of surgical complications [19]. Just recently Zhou et al. have shown that this system has a high level of reliability even if applied for children with $\mathrm{CP}$ who are known to have more frequent adverse events as well as a different profile of complications [20]. Five hips had to be excluded due to inadequate post-operative radiographic follow up. In 4 cases the radiologic documentation was not applicable and 1 patient died 7 days postoperatively due to cardiopulmonary decompensation (Table 4).

The MCPHCS was applied preoperatively and at an early followup 4 to 13 months postoperatively (median 9 months) based on AP pelvic radiographs. According to MCPHCS the parameters Reimer's MP, femoral head deformity and acetabular deformity were evaluated. In addition, Rutz' head shape classification [2] and the age- and sex-related percentiles of the acetabular index (AI) as recommended by Tönnis [21] were registered. For evaluation of the head shape one hip had to be excluded $(n=70)$ and for the measurement of the acetabular index two more hips were excluded $(n=69)$. These three patients had insufficient radiographs either preoperatively or at follow-up preventing assessment. JMP ${ }^{\circledR}$ version 13.1.0 was used for statistical analysis and visualisation. A representative case example of a 5 years and 5 months old boy who had a hip reconstruction right and VDO left is provided in Figure 1 (preoperative) as well as for the short-term (Figure 2) and midterm follow up (Figure 3).

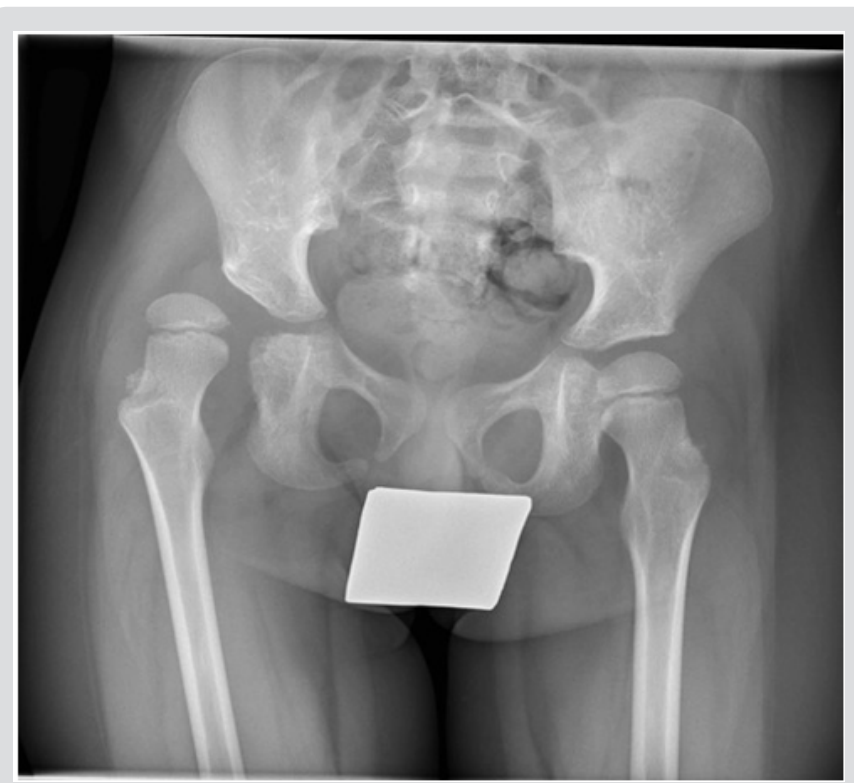

Figure 1: 5 year old boy, hip reconstruction right/VDO left, 1 day preoperative. 


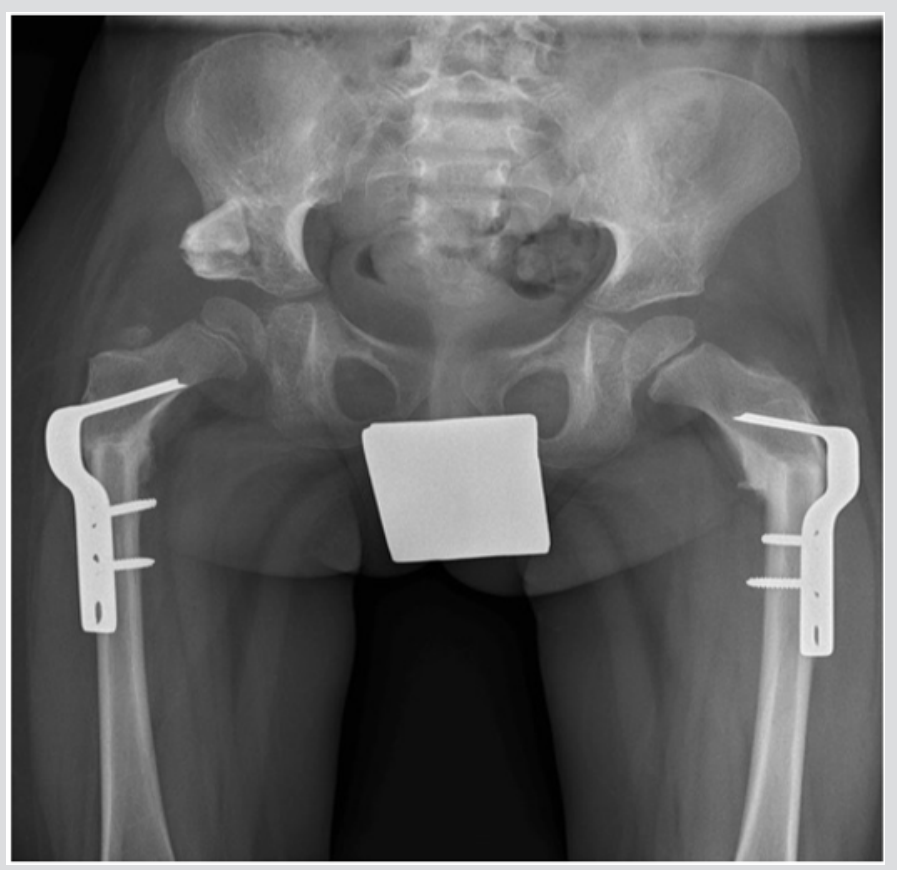

Figure 2: 5 year old boy, hip reconstruction right/VDO left, 3 months postoperative.

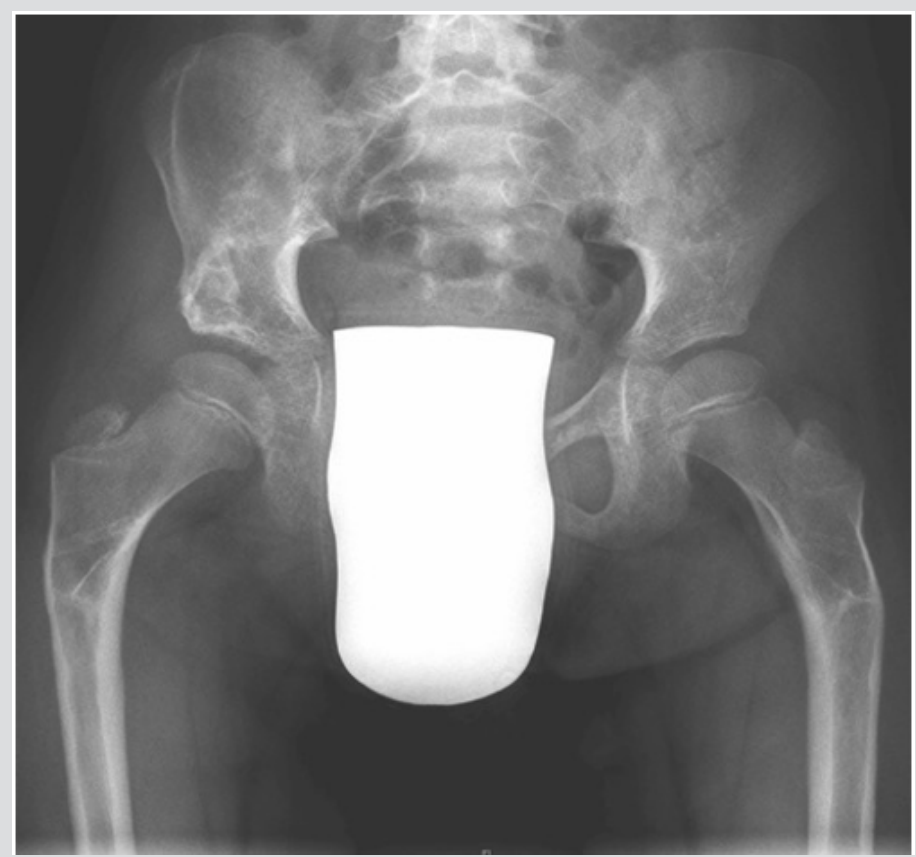

Figure 3: 5 year old boy, hip reconstruction right/VDO left, 30 months postoperative.

\section{Results}

\section{Surgical Data}

The total operation time per hip ranged between 45 and $200 \mathrm{~min}$ (median 100min).As expected, hip reconstructions tooksignificantly longer compared to isolated femoral osteotomies with durations of 75 to $200 \mathrm{~min}$ (median $115 \mathrm{~min}$ ) and 45 to $130 \mathrm{~min}$ (median $70 \mathrm{~min})$, respectively. There was a trend to shorter operation-times on the right side with 45 to $180 \mathrm{~min}$ (median 90min) compared to 60 to $200 \mathrm{~min}$ (median $105 \mathrm{~min}$ ) on the left side (Figure 4). The total blood loss per one-stage surgery ranged from 0.9 to $31.8 \mathrm{ml} /$ kgBW (median $10.4 \mathrm{ml} / \mathrm{kgBW}$ ). Grouped by the complexity of the procedures the unilateral femoral osteotomies had the least blood loss (range $0.9-1.7$, median $1.3 \mathrm{ml} / \mathrm{kgBW}$ ) followed by the bilateral femoral osteotomies (range 1.4-16.0, median $5.0 \mathrm{ml} / \mathrm{kgBW}$ ) while all procedures including a pelvic osteotomy showed a similar blood loss (unilateral hip reconstruction range 6.3-20.0, median $9.9 \mathrm{ml}$ / kgBW; hip reconstruction/contralateral femoral osteotomy range 6.0-29.8, median $11.2 \mathrm{ml} / \mathrm{kgBW}$; bilateral hip reconstruction range 8.3-31.8, median $11.4 \mathrm{ml} / \mathrm{kgBW}$ ). 


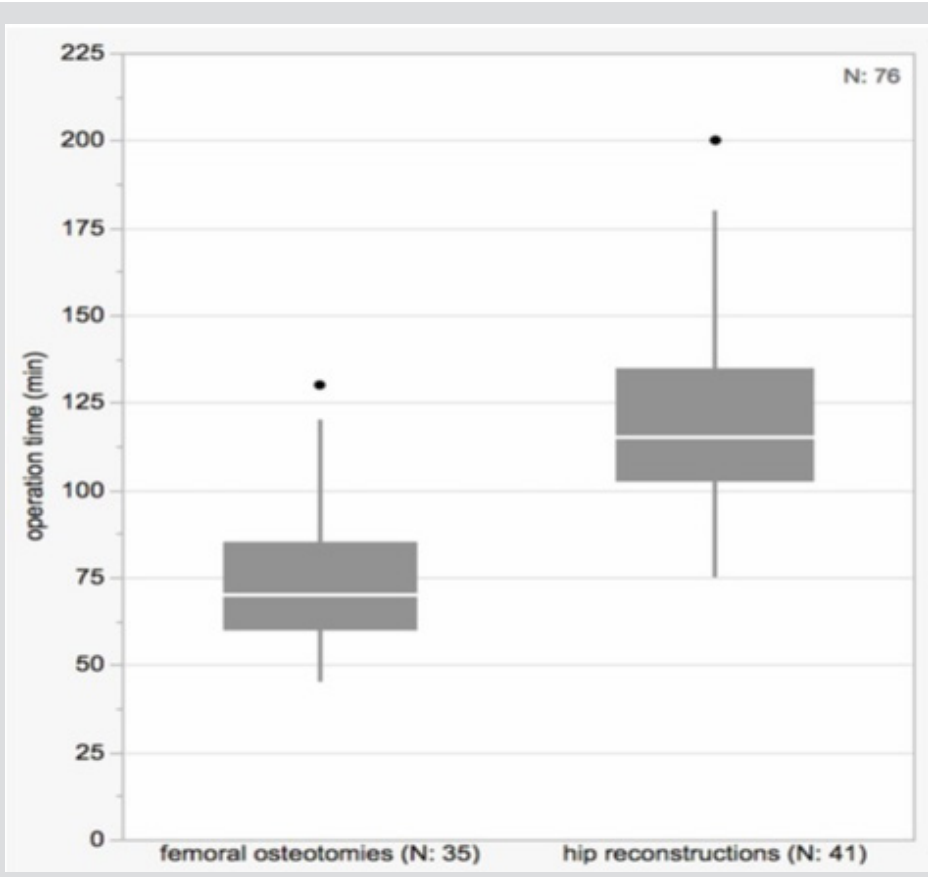

Figure 4: Operation time femoral osteotomies vs. hip reconstructions.

Blood transfusion was performed intraoperatively or during the early postoperative course in 23 of the 41 one-stage procedures (56\%). Those patients who received blood had a significantly higher blood loss than those not requiring blood transfusion (transfused 6.3-29.8, median $13.3 \mathrm{ml} / \mathrm{kgBW}$; not transfused 0.9-20.0, median $6.6 \mathrm{ml} / \mathrm{kgBW}$ ) (Figure 5). The total complication rate of the cohort according to the Clavien-Dindo classification was $70 \%$. A closer look at this tremendous rate shows that only two patients $(5 \%)$ were classified as grade I while twenty-five (61\%) reached grade
II mostly due to the necessity of blood transfusions. One patient (2\%) scored grade IV because of a complicated mechanical ileus and unfortunately one patient died 7 days postoperatively suffering from severe pneumonia, which has to be classified as grade $V$ (Table 4). Concerning radiological data, we analysed the distribution of the MCPHCS grades pre- and postoperatively (Figure 6). Preoperatively three hips (4\%) were classified as grade 1, one hip (1\%) as grade 2 , fourteen hips (20\%) as grade 3 , thirty hips (42\%) as grade 4 , six hips (9\%) as grade 5 and seventeen hips $(24 \%)$ as grade 6 .

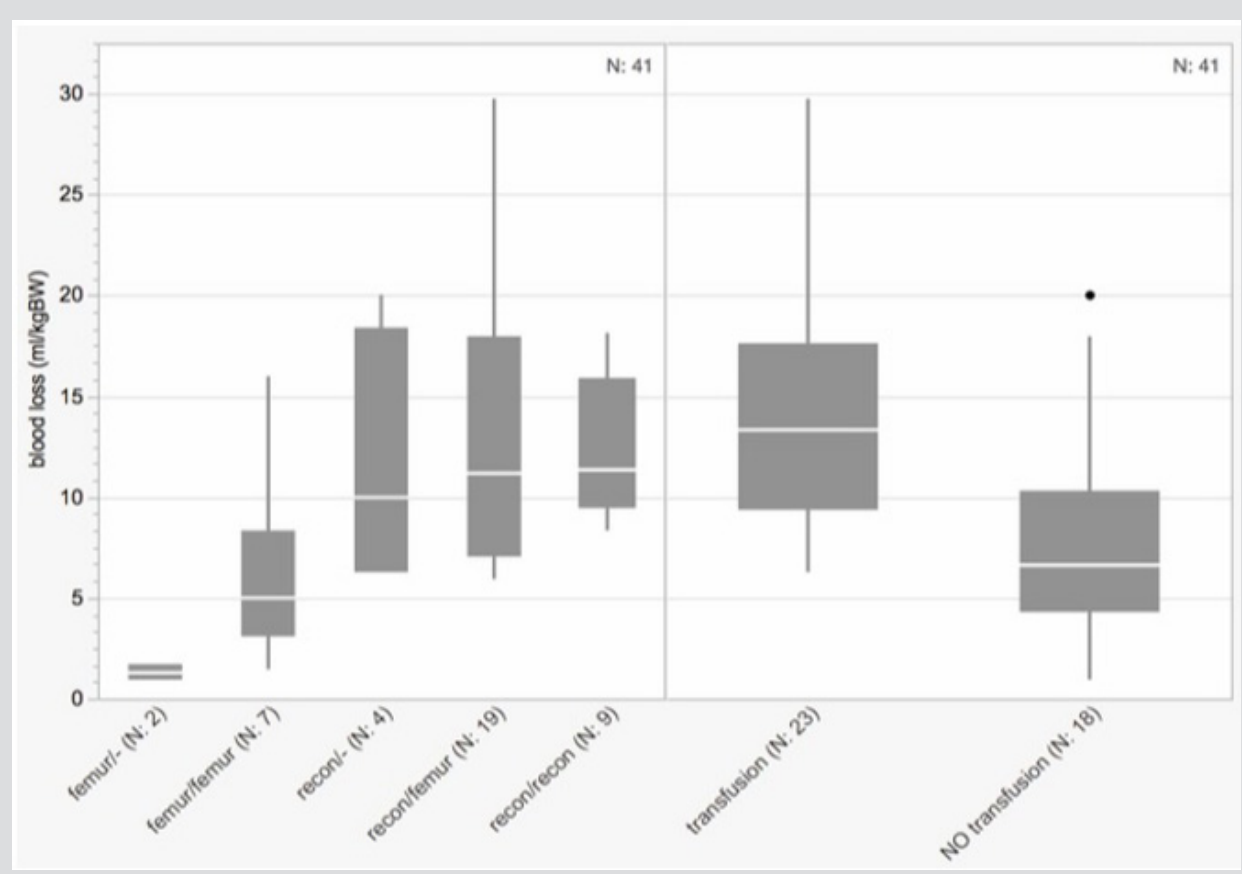

Figure 5: Blood loss by complexity of procedure and necessity of blood transfusions. 


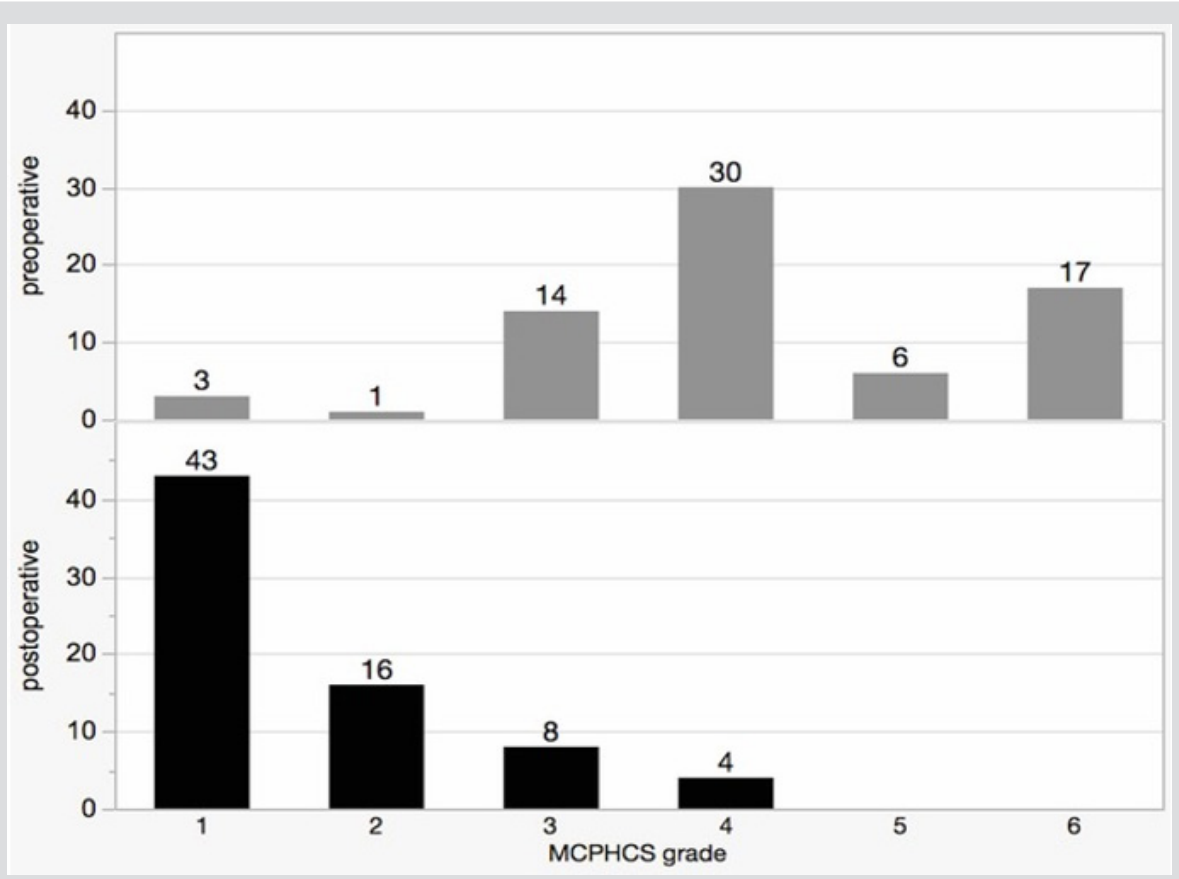

Figure 6: MCPHCS grades pre- vs. postoperative $(n=71)$.

Postoperative MCPHCS grades showed evident improvement. At follow-up forty-three hips (61\%) were grade 1, sixteen hips (22\%) grade 2, eight hips (11\%) grade 3 and four hips (6\%) grade 4. Referring to our preoperative distribution of pathologies this means that postoperatively four hips (6\%) maintained a mild subluxation, twenty-four hips (33\%) had a residual displacement and a majority of forty-three hips (61\%) could be judged as normal. The acetabular deformity was characterised according to the four categories proposed in the appendix of the MCPHCS classification (Figure 7).
Preoperatively eighteen hips (25\%) had a normal acetabulum (A0), thirty-six (51\%) appeared dysplastic (A1), eleven (16\%) showed a small "gothic arch" (A2), and six hips (8\%) had a large "gothic arch" (A3). Postoperatively there were no hips classified as A2 or A3. Twenty (28\%) stayed dysplastic while fifty-one (72\%) showed a normal acetabulum. When differentiating between those hips without $(n=33)$ and those who underwent pelvic osteotomy $(n=38)$ the effect of correction was even more impressive (Figure 8).

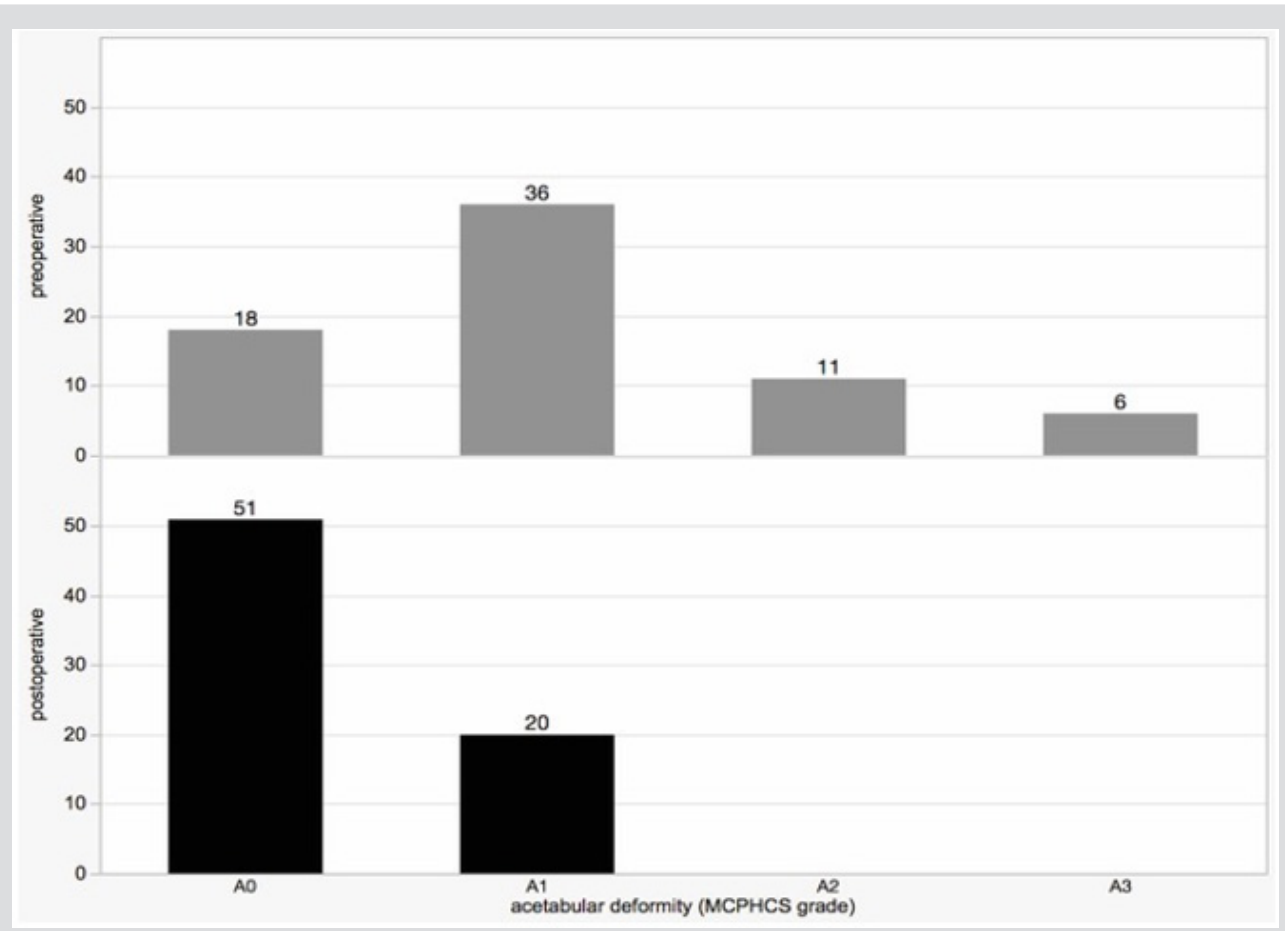

Figure 7: MCPHCS acetabular deformity pre- vs. postoperative $(n=71)$. 


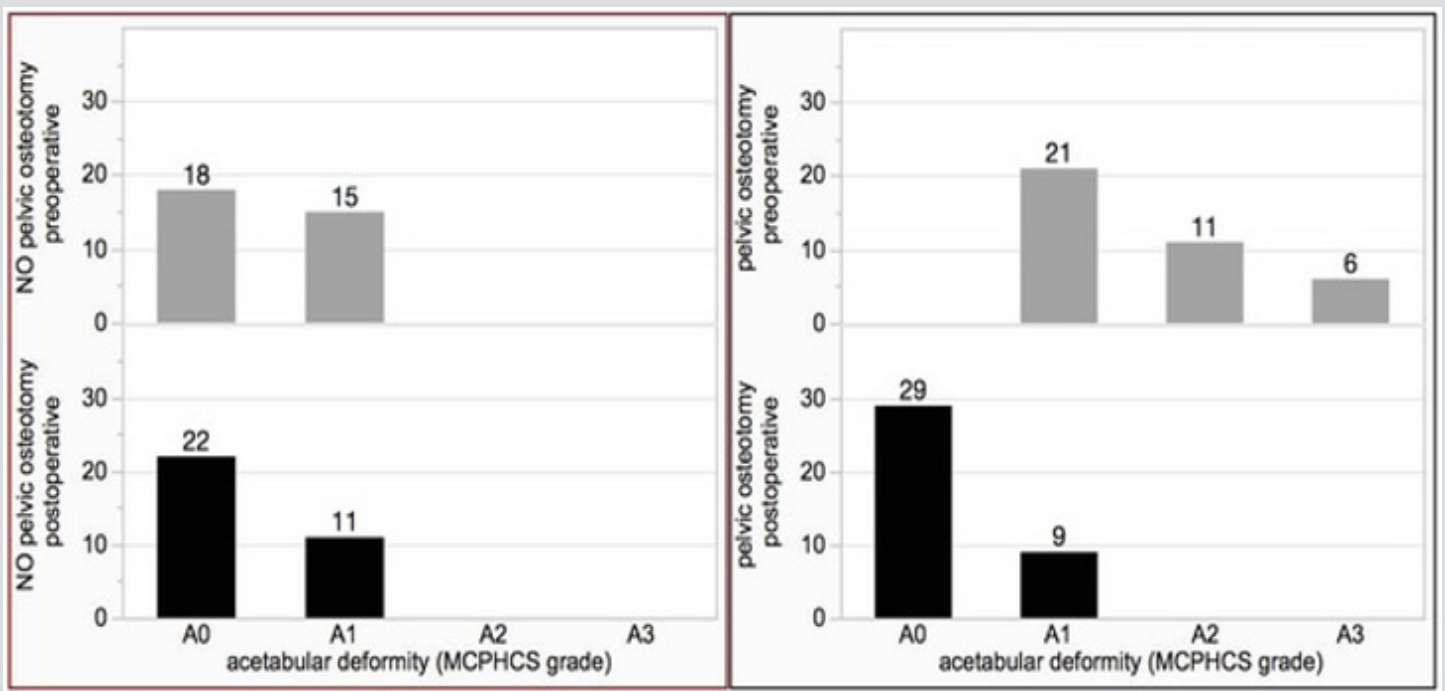

Figure 8: MCPHCS acetabular deformity related to pelvic osteotomy (no $n=33$ / yes $n=38$ ).

Eighteen (55\%) of those hips that were not addressed by pelvic osteotomy were classified as A0 preoperatively having a normal acetabulum. Fifteen (45\%) were A1. Postoperatively twenty-two of these hips (67\%) were A0 and eleven (33\%) A1. In contrast to this rather discreet improvement the hips with pelvic osteotomy showed an impressive correction of the deformity. Preoperatively twenty-one (55\%) had to be classified A1, eleven (29\%) A2, and six (16\%) A3. Postoperatively twenty-nine (76\%) were normal (A0) while nine (24\%) stayed dysplastic (A1). To allow an additional numeric understanding of the acetabular configuration and the changes from pre- to postoperative the age- and sex-related AIpercentiles were applied. Six categories were defined: $<3 \mathrm{P}, 3-10 \mathrm{P}$, 10-50P, 50-90P, 90-97P, and >97P. Concerning the preoperative distribution within our cohort there were five hips (7\%) ranging between 10-50P, eleven (16\%) 50-90P, eight (12\%) 90-97P, and forty-five $(65 \%)>97 \mathrm{P}$ (Figure 9). Postoperatively two hips (3\%) reached $<3$ P, five (7\%) 3-10P, nineteen (28\%) 10-50P, twenty-three (33\%) 50-90P, nine (13\%) 90-97P, and 11 (16\%) were still >97P.

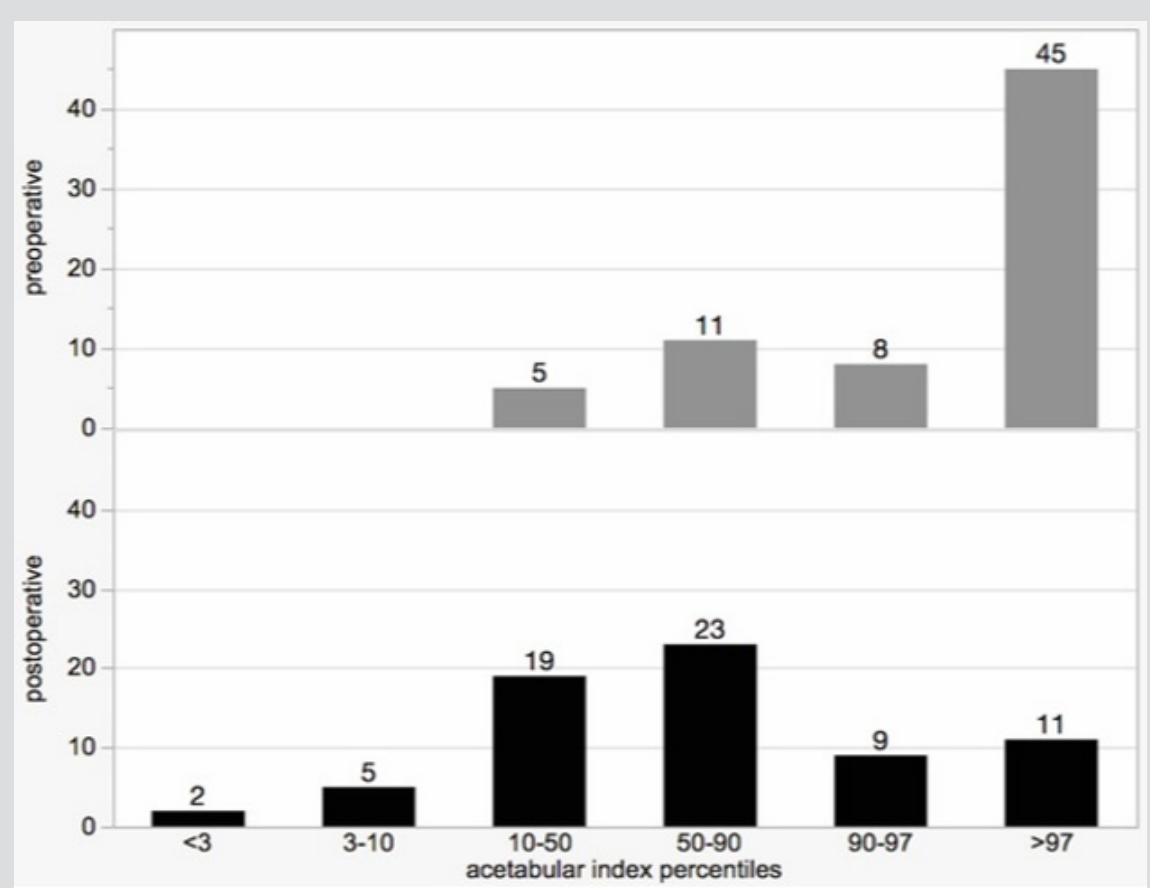

Figure 9: AI percentiles pre- vs. postoperative $(n=69)$.

We further divided our cohort according to pelvic osteotomy ( $n=37$ with; $n=32$ without) (Figure 10). The group without a pelvic intervention showed slight changes: preoperatively four hips (12\%) represented the 10-50 AI-percentile, eleven (34\%) 50-90P, five (16\%) 90-97P, and twelve (38\%) >97P. Postoperatively there were still no hips below the 10 th percentile: Nine (28\%) were 10-
50P, ten (31\%) 50-90P, six (19\%) 90-97P, and seven (22\%) >97P. In contrast, the group with pelvic osteotomy experienced obvious changes towards lower AC-percentiles. While preoperatively one (3\%) was $10-50 \mathrm{P}$, three $(8 \%)$ were $90-97 \mathrm{P}$ and the vast majority of thirty-three $(89 \%)$ were $>97 \mathrm{P}$, the postoperative distribution showed a majority of 23 hips (62\%) between the 10th and 90th 
percentile. There were two $(5 \%)<3$, five $(14 \%) 3-10 \mathrm{P}$, ten $(27 \%)$ 10-50P, thirteen (35\%) 50-90P, three (8\%) 90-97P, and four (11\%) $>97 \mathrm{P}$. These postoperative values are close to the age- and sex- related normal distribution. To evaluate the head deformity, we applied the appropriate MCPHCS grades as well as the grading according to Rutz et al. [2].

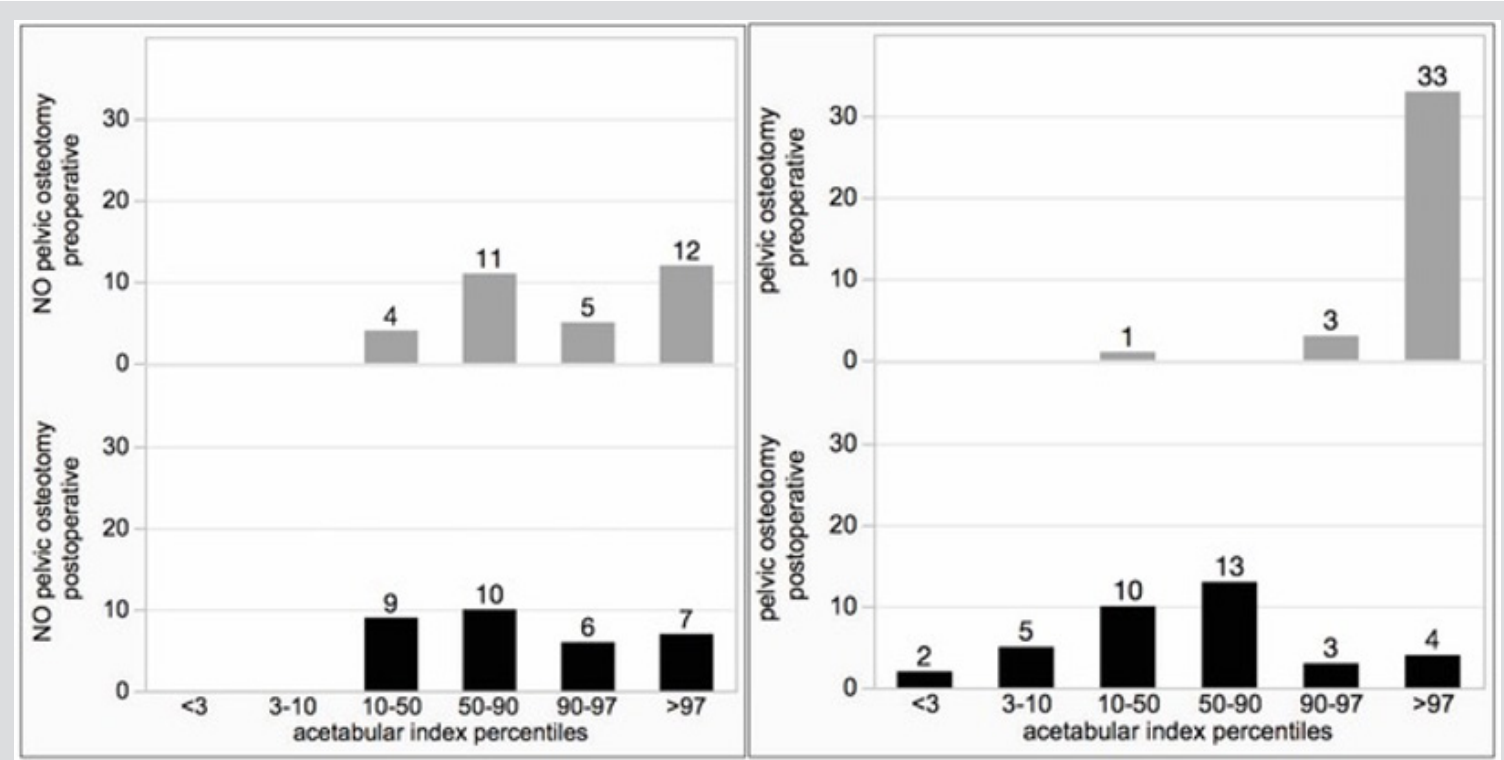

Figure 10: AI percentiles related to pelvic osteotomy (no n=32 / yes n=37).

While both classifications differentiate the normal head (MCPHCS FH0 / Rutz a) from a mild (FH1 / b), moderate (FH2 / c), and severe (FH3 / d) deformity, the MCPHCS-grading focuses on the lateral aspect of the femoral head already with mild deformity while Rutz applies this criterion within moderate deformities for the first time. Instead, the medial flattening of the head is of greater importance within Rutz's classification. This explains the differences within the pre- and postoperative distributions. 70 hips showed adequate x-ray quality and could be included. Preoperative classification according MCPHCS resulted in fifty-nine hips (84\%) with FH0 and eleven (16\%) with FH1. Postoperatively fifty-nine $(84 \%)$ were still FH0 while eight $(12 \%)$ reached FH1. Three hips (4\%) showed avascular necrosis (AVN) at the early follow up. Expressed according to Rutz's classification this means preoperatively thirty-three hips (47\%) were grade a and thirtyseven (53\%) grade b. Postoperatively there were thirty-six (53\%) grade a, thirty-one $(44 \%)$ grade $\mathrm{b}$ and again the aforementioned three hips (4\%) described as AVN. A closer look at these three hips with AVN revealed that two were preoperatively graded as FH0/a and one as FH1/b. All three hips were hip reconstructions, two of which needed open reduction. The VDOs were performed with a shortening of $15-17 \mathrm{~mm}$. At the last available follow up all three hips showed recovery. Two of them could then be classified as FH1/b (follow-up 39 and 62 months) and one hip reached FH0/a (followup 31months). No further AVN occurred in this cohort until final follow-up.

\section{Conclusion}

To our knowledge there are no comparable studies dealing with the safety and feasibility of reconstructive hip surgery in young children with $\mathrm{CP}$ especially with a focus on the perioperative and early postoperative course including the duration of surgery, blood loss, and complications. Furthermore, we evaluated the radiological data to compare MCPHCS grades, acetabular deformity, AI-percentiles, and head deformity at early follow-up. Safety is a major concern in these patients who are undernourished and often have other concomitant disease. One issue is duration of surgery and blood loss. While a unilateral femoral osteotomy required 70 mins, the operation was prolonged by 45 mins when combined with a pelvic osteotomy and open reduction. The data revealed low volumes of blood loss even in one-stage surgeries with bilateral pelvic osteotomies (median $11.4 \mathrm{ml} / \mathrm{kgBW}$ ). Looking at one-stage surgeries with femoral interventions only, we found a median blood loss of $3.2 \mathrm{ml} / \mathrm{kgBW}$. Summing up all uni- and bilateral pelvic onestage procedures the median blood loss was still as low as $10.8 \mathrm{ml} /$ kgBW.

A standard blood volume of $70 \mathrm{ml} / \mathrm{kgBW}$ is postulated for healthy children older than 2 years [22]. Even if we assume that the blood volume might be slightly diminished in our patients with CP the blood loss remained comfortably lower than one third $(23 \mathrm{ml} /$ $\mathrm{kgBW}$ ) in our cohort. Twenty-five to thirty percent blood loss can be considered the threshold for transfusion of red cells to prevent haemorrhagic shock [23]. Those patients who were indicated for blood transfusion by our anesthesiologists showed a blood loss of $13.3 \mathrm{ml} / \mathrm{kgBW}$ while those without transfusion showed an impressively lower blood loss of $6.6 \mathrm{ml} / \mathrm{kgBW}$. Considering all this data we think that an early bony intervention for these patients is acceptable. We set the limit for blood transfusion at a haemoglobin concentration of $80 \mathrm{~g} / \mathrm{l}$ for these patients. This results from our clinical experience that other blood substitutes are poorly tolerated by patients with low levels of physical activity. As a result, we now have few pulmonary complications since we became more generous with transfusions. In two patients, blood loss exceeded the critical one third of total blood volume. 
However, estimation of intraoperative blood loss is unreliable, and hence perioperative fluid management and transfusion is more reliably guided by clinical examination, hemodynamics, hematocrit and hemoglobin-levels. Therefore, we feel an ICU should be available for management of these patients post-operatively. At first sight the overall complication rate of $70 \%$ is quite high especially because Clavien-Dindo Grades I and patients with blood transfusions (Grade II) are included. Excluding these cases, the complication rate is still $23 \%$ including one death from pneumonia (2.4\%), quite high compared to surgery in a healthy cohort. This is in accordance to the higher risk estimation reflected by the distribution of the ASA classification (17 status II, 22 status III) and the low body weight in more than $30 \%$ of the cohort. Apart from pulmonary complications a few gastroenterological complications occurred but we do not view these as direct complications of the surgical procedure. Postoperative surveillance on the ICU is additionally supportive of these complex patients with optimization of respiratory function, strict monitoring of nutrition and analgesia.

Pressure ulcers are a recognised complication of spica casts however we find them beneficial in easing pain by reducing uncontrolled movements in the early postoperative course. We reduced the time in castalready to two weeks only if at all. Evaluation of pre- and postoperative MCPHCS grades showed correction of the majority of hips to normal. For acetabular deformity, according to the MCPHCS definition none of the hips were left with a gothic arch but $28 \%$ stayed dysplastic. Expressed in age- and sex-related AIpercentiles we found that eleven hips (16\%) remained above the $97^{\text {th }}$ percentile. Most of them (7 hips) were found in hips where no pelvic osteotomy was performed. Those hips where a pelvic osteotomy was performed showed a postoperative distribution of percentiles near normal. This data probably suggests that pelvic osteotomy should be performed more frequently. The last parameter to discuss is the pre- and postoperative femoral head deformity. Applying the MCPHCS grading and Rutz's classification we found that the latter was more sensitive in discreet deformities. Whether this is relevant will stay a contentious issue.

However, no patient presented with a severe destruction of the femoral head. As long as the deformity is minor a recovery of the shape can be expected once the hip is centred. This does not affect the description of AVNs, which occurred in 3 femoral heads. In our opinion sufficient shortening during the proximal femoral osteotomy is an essential part of early bony intervention to prevent AVNs by minimising intraarticular pressure. Fortunately, at midterm follow-up all three of these hips showed sufficient recovery. This retrospective study has some limitations. As shown in the patient demographics and despite carefully applied inclusion criteria the cohort is still quite heterogeneous due to the nature of CP. A few hips had to be excluded from the radiologic evaluation because of insufficient or absent radiographs at follow-up. Different bony procedures were included as indicated. Only long-term follow-up will show, however, in how far such early operations are worthwhile. Earlier intervention is easier and faster as less deformity is present, and therefore we expect a better outcome compared to later intervention.
It further needs to be shown that these patients who present hip problems already so early in life, have less problems and complications when operated a few years later. We conclude that young patients with cerebral palsy present a higher risk for surgery. Blood transfusion should be considered and an ICU available. As the complications mainly involve epilepsy, bowel and lung problems a team of respective specialists should be available.

\section{Declarations}

Ethics Approval and Consent to Participate: This study was approved under the audit provisions oft he institution's Ethics in Human Research Committee, EKBB Number EK 22/07 in 08/2014. Please find the related pdf attached to the submission. Written consent has been obtained from the participants.

Consent for Publication: Not applicable, there is no identifying material included in this publication.

Availability of Data and Materials: All data generated or analysed during this study are included in this published article.

Competing Interest: No financial or nonfinancial benefits have been received or will be received from any party related directly or indirectly to the subject of the article.

\section{Authors' Contributions}

The authors contributed to this paper according to the following criteria. Design of the study: MJK, ER; Data collection: MJK, RB, ER; Data analysis and interpretation: MJK, ER; Draft of this article: MJK; Critical revision of the article: RB, ER; Final approval of the version to be published: MJK, RB, ER.

\section{References}

1. Soo B, Howard JJ, Boyd RN, Reid SM, Lanigan A, et al. (2006) Hip displacement in cerebral palsy. The Journal of bone and joint surgery. American volume 88(1): 121-129.

2. Rutz E, Vavken P, Camathias C, Haase C, Jünemann S, et al. (2015) Longterm results and outcome predictors in one-stage hip reconstruction in children with cerebral palsy. The Journal of bone and joint surgery. American volume 97(6): 500-506.

3. Palisano R, Rosenbaum P, Walter S, Russell D, Wood E, et al. (1997) Development and reliability of a system to classify gross motor function in children with cerebral palsy. Developmental medicine and child neurology 39(4): 214-223.

4. Wawrzuta J, Willoughby KL, Molesworth C, Ang SG, Shore BJ, et al. (2016) Hip health at skeletal maturity: a population-based study of young adults with cerebral palsy. Developmental medicine and child neurology 58(12): 1273-1280.

5. Burns F, Stewart R, Reddihough D, Scheinberg A, Ooi K, et al. (2014) The cerebral palsy transition clinic: administrative chore, clinical responsibility, or opportunity for audit and clinical research? Journal of children's orthopaedics 8(3): 203-213.

6. Robin J, Graham HK, Baker R, Selber P, Simpson P, et al. (2009) A classification system for hip disease in cerebral palsy. Developmental medicine and child neurology 51(3): 183-192.

7. Dhawale AA, Karatas AF, Holmes L, Rogers KJ, Dabney KW, et al. (2013) Long-term outcome of reconstruction of the hip in young children with cerebral palsy. The bone \& joint journal 95-B(2): 259-265.

8. Graham HK, Boyd R, Carlin JB, Dobson F, Lowe K, et al. (2008) Does botulinum toxin A combined with bracing prevent hip displacement 
in children with cerebral palsy and "Hips at Risk"? Journal of Bone and Joint Surgery-American Volume 90(1): 23-33.

9. Shore BJ, Yu X, Desai S, Selber P, Wolfe R, et al. (2012) Adductor surgery to prevent hip displacement in children with cerebral palsy: the predictive role of the Gross Motor Function Classification System. The Journal of bone and joint surgery. American volume 94(4): 326-334.

10. Reimer J (1980) The stability of the hip in children. A radiological study of the results of muscle surgery in cerebral palsy. Acta orthopaedica Scandinavica. Supplementum 184: 1-100.

11. Saklad M (1941) Grading of Patients for Surgical Procedures. Anesthesiology 2: 281-284

12. WHO Expert Committee on Physical Status: The Use and Interpretation of Anthropometry. Physical status : the use and interpretation of anthropometry : report of a WHO Expert Committee. WHO technical report series $\mathrm{x}$, pp. 452 .

13. Freedman DS, Sherry B (2009) The validity of BMI as an indicator of body fatness and risk among children. Pediatrics 124(Suppl 1): S23-34.

14. Murnaghan ML, Simpson P, Robin JG, Shore BJ, Selber P, et al. (2010) The cerebral palsy hip classification is reliable: an inter- and intra-observer reliability study. J Bone Joint Surg Br 92: 436-441.

15. Eilert RE, Mac Ewen GD (1977) Varus derotational osteotomy of the femur in cerebral palsy. Clin Orthop Relat Res 125: 168-172.

16. Beauchesne R, Miller F, Moseley C (1992) Proximal femoral osteotomy using the AO fixed-angle blade plate. Journal of pediatric orthopedics 12(6): 735-740.

\section{ISSN: 2574-1241}

DOI: 10.26717/BJSTR.2019.17.002946

Manuel Johannes Kraus. Biomed J Sci \& Tech Res

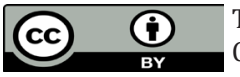

This work is licensed under Creative Commons Attribution 4.0 License

Submission Link: https://biomedres.us/submit-manuscript.php
17. Brunner R, Baumann JU (1977) Long-term effects of intertrochanteric varus-derotation osteotomy on femur and acetabulum in spastic cerebral palsy: an 11- to 18-year follow-up study. Journal of pediatric orthopedics 17(5): 585-591.

18. Rutz E, Brunner R (2010) The pediatric LCP hip plate for fixation of proximal femoral osteotomy in cerebral palsy and severe osteoporosis. Journal of pediatric orthopedics 30(7): 726-731.

19. Clavien PA, Barkun J, De Oliveira ML, Vauthey JN, Dindo D, et al. (2009) The Clavien-Dindo classification of surgical complications: five-year experience. Annals of surgery 250(2): 187-196.

20. Zhou L, Willoughby K, Strobel N, Thomason P, Gallagher C, et al. (2018) Classifying Adverse Events Following Lower Limb Orthopaedic Surgery in Children with Cerebral Palsy: Reliability of the Modified ClavienDindo System. Journal of pediatric orthopedics.

21. Neidel J, Tonnis D (1994) [Percentile graphs in the documentation of acetabular angle in children with hip dysplasia. A tool in the diagnosis and quality control of its treatment]. Zeitschrift fur Orthopadie und ihre Grenzgebiete 132(6): 512-515.

22. Bharadwaj A, Khandelwal M, Bhargava SK (2014) Perioperative neonatal and paediatric blood transfusion. Indian J Anaesth 58(5): 652-657.

23. Kaur P, Basu S, Kaur G, Kaur R (2011) Transfusion protocol in trauma. J Emerg Trauma Shock 4(1): 103-108.

$\begin{array}{ll}\text { BIOMEDICAL } & \text { Assets of Publishing with us } \\ \text { RESEARCHES } & \text { - Global archiving of articles } \\ & \text { - Immediate, unrestricted online access } \\ \end{array}$

